\title{
Preparation and visible-light photocatalytic activity of $\mathrm{Ag}_{3} \mathrm{VO}_{4}$ powders
}

\author{
Xuexiang $\mathrm{Hu}$, Chun $\mathrm{Hu}^{*}$ \\ State Key Laboratory of Environmental Aquatic Chemistry, Research Center for Eco-Environmental Sciences, \\ Chinese Academy of Sciences, No. 18, Shuangqinglu, Beijing 100085, China
}

Received 14 July 2006; received in revised form 23 November 2006; accepted 27 November 2006

Available online 9 December 2006

\begin{abstract}
Monoclinic structure $\mathrm{Ag}_{3} \mathrm{VO}_{4}$ was prepared by precipitation method and evaluated for the decolorization of azodye acid red $\mathrm{B}$ (ARB) under visible light irradiation $(\lambda>420 \mathrm{~nm})$. The $\mathrm{Ag}_{3} \mathrm{VO}_{4}$ prepared in the excess vanadium or silver exhibited higher visible-light-driven activity than the sample prepared in a stoichiometric ratio. X-ray diffraction and UV-vis diffuse reflectance measurements indicated that the excess vanadium or silver in the preparation increased the crystallinity and absorbance in visible light region, resulting in an increase in the photocatalytic efficiency. Furthermore, the activity of the $\mathrm{Ag}_{3} \mathrm{VO}_{4}$ was increased by 3.8 times when a $\mathrm{NiO}$ was loaded. It was due to the formation of a short-circuited microphotoelectrochemical cell on the surface of $\mathrm{NiO} / \mathrm{Ag}_{3} \mathrm{VO}_{4}$, enhancing the separation of photogenerated electron-hole pairs, which was proved by ESR studies.
\end{abstract}

(C) 2006 Elsevier Inc. All rights reserved.

Keywords: $\mathrm{Ag}_{3} \mathrm{VO}_{4}$; Precipitation method; Visible-light-driven photocatalyst; Azodye

\section{Introduction}

Photocatalysis is a promising technology for the treatment of contaminants, especially for the removal of organic compounds with solar energy [1]. To date, titanium dioxide $\left(\mathrm{TiO}_{2}\right)$ has undoubtedly been proven to be the most excellent photocatalyst for the oxidative decomposition of many organic compounds under UV irradiation [2-4]. However, the fast recombination rate of photogenerated electron-hole pairs hinders the commercialization of this technology $[5,6]$. Furthermore, $\mathrm{TiO}_{2}$ only active under UV irradiation limits its application [7]. Numerous studies have attempted to develop visible-light-driven photocatalysts in order to utilize solar energy and indoor light efficiently [8-12]. There are usually two ways [13] to exploit photocatalysts responsive to visible light irradiation: One way is to generate intermediate energy levels in UV-active photocatalysts by doping other elements. However, this way is not so effective because dopants will serve as sites for electron-hole recombination to decrease photocatalytic activity. Another way is to develop new materials with

\footnotetext{
${ }^{*}$ Corresponding author. Fax: + 861062923541 .

E-mail address: huchun@rcees.ac.cn (C. Hu).
}

photocatalytic activity under visible light irradiation. Since Zou et al. [14] reported water splitting for $\mathrm{H}_{2}$ and $\mathrm{O}_{2}$ evolution in a stoichiometric amount over the $\mathrm{NiO}_{x} /$ $\mathrm{In}_{0.9} \mathrm{Ni}_{0.1} \mathrm{TaO}_{4}$ photocatalyst under visible light irradiation, many new visible-light-driven catalysts have also been reported [13,15-22]. However, only a few [13,20-22] have been investigated with the aim to eliminate organic pollutants in water so far. The photocatalytic decomposition of organic contaminants requires that the valence band (VB) of the photocatalyst must meet the potential level of oxidizing the organic contaminants. Otherwise the photocatalyst would have no visible-light-driven activity for the eliminating organics even if it has absorbance in visible light region. Konta et al. [23] prepared silver vanadates $\left(\alpha-\mathrm{AgVO}_{3}, \beta-\mathrm{AgVO}_{3}, \mathrm{Ag}_{4} \mathrm{~V}_{2} \mathrm{O}_{7}\right.$ and $\left.\mathrm{Ag}_{3} \mathrm{VO}_{4}\right)$ by precipitation and solid-state reactions and further investigated the photocatalytic activity for $\mathrm{O}_{2}$ evolution. All silver vanadates showed intense absorption bands in the visible light region. However, among them, only $\mathrm{Ag}_{3} \mathrm{VO}_{4}$ possessed a photocatalytic activity for $\mathrm{O}_{2}$ evolution from an aqueous silver nitrate solution under visible light irradiation. Holes photogenerated in $\mathrm{Ag}_{3} \mathrm{VO}_{4}$ can migrate to the reaction sites on the surface more easily than those of other silver vanadates, and oxidize $\mathrm{H}_{2} \mathrm{O}$ to form 
$\mathrm{O}_{2}$. It indicated that its $\mathrm{VB}$ is more positive than the $\mathrm{O}_{2} /$ $\mathrm{H}_{2} \mathrm{O}$ potential level $(1.23 \mathrm{~V}$ vs. SHE, $\mathrm{pH}=0)$. So, the photocatalyst with a strong oxidizing potential can be postulated and expected to be good candidate to decompose organic compounds [24].

In the present work, $\mathrm{Ag}_{3} \mathrm{VO}_{4}$ was synthesized via precipitation reaction. Most of the azodyes are known to inhibit biological treatment of wastewater from the textile or dyeing industry [25]. ARB, a widely used anionic monoazo-dye, was selected as model chemical to evaluate the activity and properties of the catalyst. Moreover, the photocatalytic activity of $\mathrm{Ag}_{3} \mathrm{VO}_{4}$ was evaluated by the photodegradation of ARB under visible light irradiation. Effects of the ratio of starting materials and $\mathrm{NiO}$ loading on the photocatalytic activity of $\mathrm{Ag}_{3} \mathrm{VO}_{4}$ were investigated.

\section{Experimental}

\subsection{Materials}

Spin trap 5,5-dimethyl-1-pyrroline- $N$-oxide (DMPO) was purchased from the Sigma Chemical Co. Azodye acid red B (ARB) was kindly supplied by the Shanghai Chemical Co. and were used without further purification. All other chemicals were analytical grade reagents without further purification. Deionized and doubly distilled water was used throughout this study.

\subsection{Preparation}

$\mathrm{NaOH}$ and $\mathrm{V}_{2} \mathrm{O}_{5}$ powders in mole ratio $6: 1$ were put into a beaker with $20 \mathrm{~mL}$ distilled water, and magnetically stirred. Subsequently, the solution of $\mathrm{AgNO}_{3}$ was added. Yellow precipitates appeared immediately. The chemical equation is shown as follows:

$\mathrm{V}_{2} \mathrm{O}_{5}+6 \mathrm{OH}^{-} \rightarrow 2 \mathrm{VO}_{4}{ }^{3-}+3 \mathrm{H}_{2} \mathrm{O}$

$3 \mathrm{Ag}^{+}+\mathrm{VO}_{4}{ }^{3-} \rightarrow \mathrm{Ag}_{3} \mathrm{VO}_{4}$

In our experiments, the ratio of sliver to vanadium in the precursor solution varied from silver-rich $(\mathrm{Ag} / \mathrm{V}=6: 1$ for sample S1) to stoichiometric $(\mathrm{Ag} / \mathrm{V}=3: 1$ for sample $\mathrm{S} 2)$, and vanadium-rich $(\mathrm{Ag} / \mathrm{V}=3: 2$ for sample $\mathrm{S} 3)$. The precipitate was aged at room temperature for $24 \mathrm{~h}$, washed with deionized water. The obtained sample was dried at $70{ }^{\circ} \mathrm{C}$ and then calcined at $380^{\circ} \mathrm{C}$ for $4 \mathrm{~h}$.

Subsequently, a $\mathrm{NiO}$ cocatalyst was loaded by an impregnation method from an aqueous solution of $\mathrm{Ni}\left(\mathrm{NO}_{3}\right)_{2}$ in a similar manner as described elsewhere [26]. $\mathrm{Ag}_{3} \mathrm{VO}_{4}(0.5 \mathrm{~g})$ powder and appropriate amount of $\mathrm{Ni}\left(\mathrm{NO}_{3}\right)_{2}$ aqueous solution were put into a porcelain crucible. Water was evaporated at $70{ }^{\circ} \mathrm{C}$. The suspension was stirred using a glass rod during the evaporation. The dried powder was calcined at $300^{\circ} \mathrm{C}$ for $1 \mathrm{~h}$ in air using a muffle furnace. The weight percent of $\mathrm{Ni}$ was calculated by the ratio of the dosage of $\mathrm{Ni}^{2+}$ to the total amount of the dosage of $\mathrm{Ag}_{3} \mathrm{VO}_{4}$ and $\mathrm{NiO}\left(\mathrm{Ni}^{2+}\right.$ was expected to be $\mathrm{NiO}$ ).

\subsection{Characterization}

Purity and crystallinity of the as-prepared sample was obtained by powder X-ray diffraction (XRD) with a Scintag-XDS-2000 diffractometer using $\mathrm{CuK} \alpha \quad(\lambda=$ $1.5418 \AA$ ) radiation. The XRD data were collected in a scan mode with a step length of 0.05 and a preset time of $60 \mathrm{~s} / \mathrm{step}$. The accelerating voltage and the applied current were $40 \mathrm{kV}$ and $10 \mathrm{~mA}$, respectively. Morphologies and structures of the prepared samples were observed using a Hitachi S-3000N scanning electron microscopy (SEM). UV-vis diffuse reflectance spectra (UV-vis DRS) of the samples were measured by using a Hitachi UV-3010 spectrophotometer. $\mathrm{BaSO}_{4}$ was used as a reference standard, and the spectra were recorded in the range 200-800 nm. Electron spin resonance (ESR) spectra were obtained using a Bruker model ESP 300 E electron paramagnetic resonance spectrometer equipped with a quanta-Ray Nd:YAG laser system as the irradiation light source $(\lambda=532 \mathrm{~nm})$. The settings were center field, $3480.00 \mathrm{G}$; microwave frequency, $9.79 \mathrm{GHz}$; and power, $5.05 \mathrm{~mW}$. Total organic carbon of the solution was analyzed with the Phoenix 8000 TOC analyzer.

\subsection{Photocatalytic experiments}

The photocatalytic activities of the synthesized powders were evaluated by photocatalytic decomposition of $\mathrm{ARB}$ in $\mathrm{Ag}_{3} \mathrm{VO}_{4}$ aqueous suspension under visible light irradiation. The light source for photocatalysis was a $350-\mathrm{W}$ Xe arc lamp (Shanghai Photoelectron Device Ltd.). Light passed through a water filter and a UV cutoff filter $(\lambda>420 \mathrm{~nm})$ and then was focused onto a $100-\mathrm{mL}$ beaker. The average light intensity was $2.5 \mathrm{~mW} / \mathrm{cm}^{2}$. The reaction temperature was maintained at $25^{\circ} \mathrm{C}$. In a typical experiment, aqueous suspensions of ARB $(60 \mathrm{~mL}, 30 \mathrm{mg} / \mathrm{L})$ and $100 \mathrm{mg}$ of catalyst powders were placed in the beaker. Prior to irradiation, the suspensions were magnetically stirred in dark for $30 \mathrm{~min}$ to establish adsorption/desorption equilibrium between the dye and the surface of the catalyst under room air equilibrated conditions. At given irradiation time intervals, 3-mL aliquots were collected, centrifuged, and then filtered through a Millipore filter (pore size $0.22 \mu \mathrm{m}$ ) to remove the catalyst particulates for analysis. The filtrates were monitored by measuring the absorbance at $\lambda=514 \mathrm{~nm}$ with a $752 \mathrm{~N}$ UV-vis spectrophotometer (Shanghai Precision \& Scientific Instrument Co. Ltd., China) to determine ARB concentration and to follow its kinetics of decolorization with time of irradiation.

Gas chromatography/mass spectroscopy (GC-MS) analysis was carried out on an Agilent 6890GC/5973MSD with a DB-5 MS capillary column. Sample was prepared by the following procedure. After irradiation $8 \mathrm{~h}$, the ARB-NiO/ $\mathrm{Ag}_{3} \mathrm{VO}_{4}$ suspensions were filtered to remove catalyst 
particles. Water was removed by freeze-dried method. The final residue was trimethylsilylated with $0.2 \mathrm{~mL}$ of anhydrous pyridine, $0.1 \mathrm{~mL}$ of hexamethyldisilazane, and $0.05 \mathrm{~mL}$ of chlorotrimethylsilane at room temperature. The mixture was shaken vigorously for about $1 \mathrm{~min}$ and was then allowed to stand for $5 \mathrm{~min}$ at room temperature. Precipitate was separated by centrifugation prior to chromatographic analysis. The temperature program of the column was as follows: at $80^{\circ} \mathrm{C}$, hold time $=20 \mathrm{~min}$; from $80^{\circ} \mathrm{C}$ to $280^{\circ} \mathrm{C}$, rate $=3.5^{\circ} \mathrm{C} / \mathrm{min}$.

\section{Results and discussion}

\subsection{Characterization}

XRD is used to investigate the phase structures of the asprepared powders. Fig. 1 shows the XRD patterns of samples prepared at different ratios of silver to vanadium in the starting material. Clearly, three samples prepared under different conditions showed similar peaks of the XRD patterns, which were readily indexed to a monoclinic phase $\mathrm{Ag}_{3} \mathrm{VO}_{4}$ (JCPDS no.43-0542). The refined cell parameters of the monoclinic phases are listed in Table 1. However, the diffraction peaks intensities of the sample

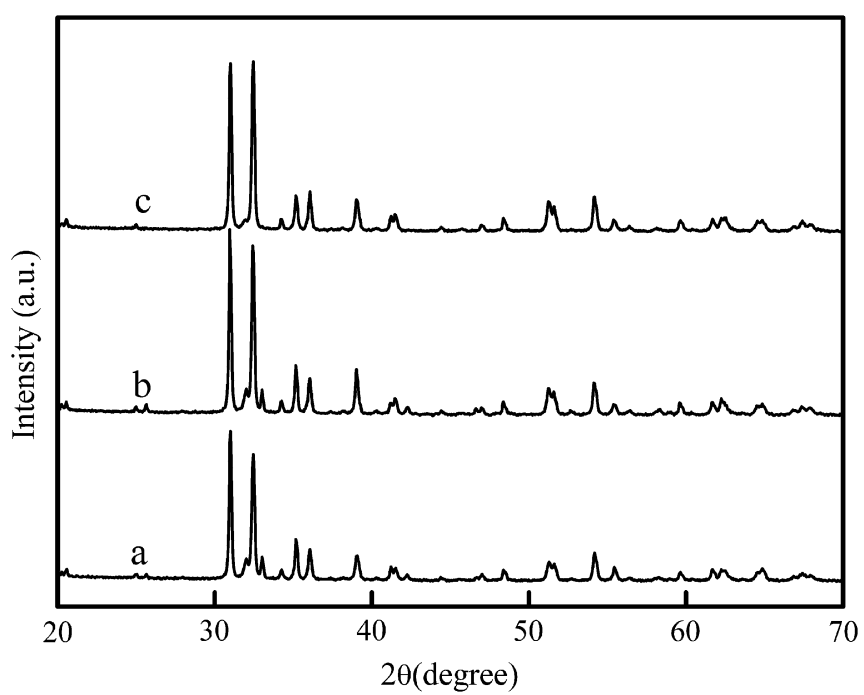

Fig. 1. XRD patterns of samples prepared (a) in a stoichiometric ratio, (b) in the presence of excess silver, and (c) in the presence of excess vanadium. prepared in the excess silver (S1) and prepared in the excess vanadium (S3) are stronger than the ones in the stoichiometric ratio (S2), indicating the increase of the crystallinity of $\mathrm{Ag}_{3} \mathrm{VO}_{4}$ prepared under the excess silver and vanadium conditions. In addition, the XRD patterns of samples prepared in excess silver or stoichiometric ratio showed a small amount of impurity at $32.99^{\circ}$, assigned to $\mathrm{Ag}_{2} \mathrm{O}$ (JCPDS no. 41-1104).

Figs. 2a-c shows the SEM photographs of $\mathrm{Ag}_{3} \mathrm{VO}_{4}$ prepared under different conditions. No noticeable difference in crystal shape among the three samples was observed. The particles of $\mathrm{Ag}_{3} \mathrm{VO}_{4}$ were all irregular rugged shape. However, the particle in stoichiometric ratio is bigger than the others. Fig. 3 shows the UV-vis diffuse reflectance spectra of the three samples. They absorbed in $\mathrm{UV}$ and visible light region. The difference in absorption edge wavelength for $\mathrm{Ag}_{3} \mathrm{VO}_{4}$ clearly indicates that three samples have different band gap. To have a quantitative estimate of the band gap energies, the absorption onsets of the samples were determined by linear extrapolation from the infection point of the curve to the baseline [27]. The absorption edge of the $\mathrm{Ag}_{3} \mathrm{VO}_{4}$ in $\mathrm{S} 1$ is about $580 \mathrm{~nm}$, the band gap is estimated to be $2.14 \mathrm{eV}$, while the edge of the absorption of the both samples in S2 and S3 is shifted to approximately $600 \mathrm{~nm}$, corresponding to a band gap energy of $2.06 \mathrm{eV}$.

\subsection{Photocatalytic activity of $\mathrm{Ag}_{3} \mathrm{VO}_{4}$ under visible light irradiation}

Fig. 4 shows the photocatalytic activity of as-prepared $\mathrm{Ag}_{3} \mathrm{VO}_{4}$ with different ratio of silver to vanadium in the starting material under visible light irradiation. The activity of S1 was similar with S3, and the activity of S2 is lowest. The decoloration ratio reached $73.29 \%, 43.19 \%, 71.28 \%$ for S1, S2 and S3, respectively, in $100 \mathrm{~min}$ irradiation. In contrast, ARB is not degraded under visible irradiation in the absence of photocatalyst. Moreover, ARB degradation over $\mathrm{TiO}_{2}$ was also performed under the same conditions. The ARB was hardly degraded by self-photosensitization process of dyes over $\mathrm{TiO}_{2}$ under visible light irradiation. The results implied that the transformation of photoelectrons from the excited state of $\mathrm{ARB}$ to the $\mathrm{CB}$ of the catalyst could be ignored under these experimental

Table 1

Lattice constant, particle size and band gap of $\mathrm{Ag}_{3} \mathrm{VO}_{4}$ samples at different $\mathrm{Ag} / \mathrm{V}$ ratios

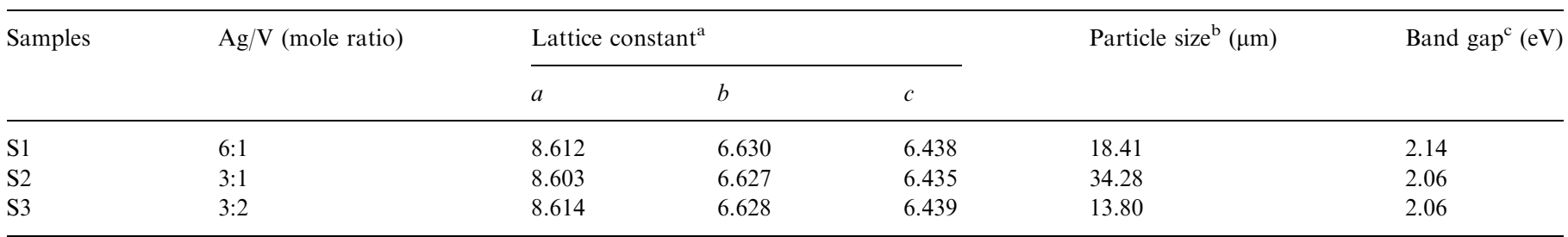

${ }^{\mathrm{a}}$ Calculated by least-squares refinement of powder XRD date.

${ }^{\mathrm{b}}$ Calculated by SEM images.

${ }^{\mathrm{c}}$ Calculated using the absorption edge of the UV-vis DRS. 

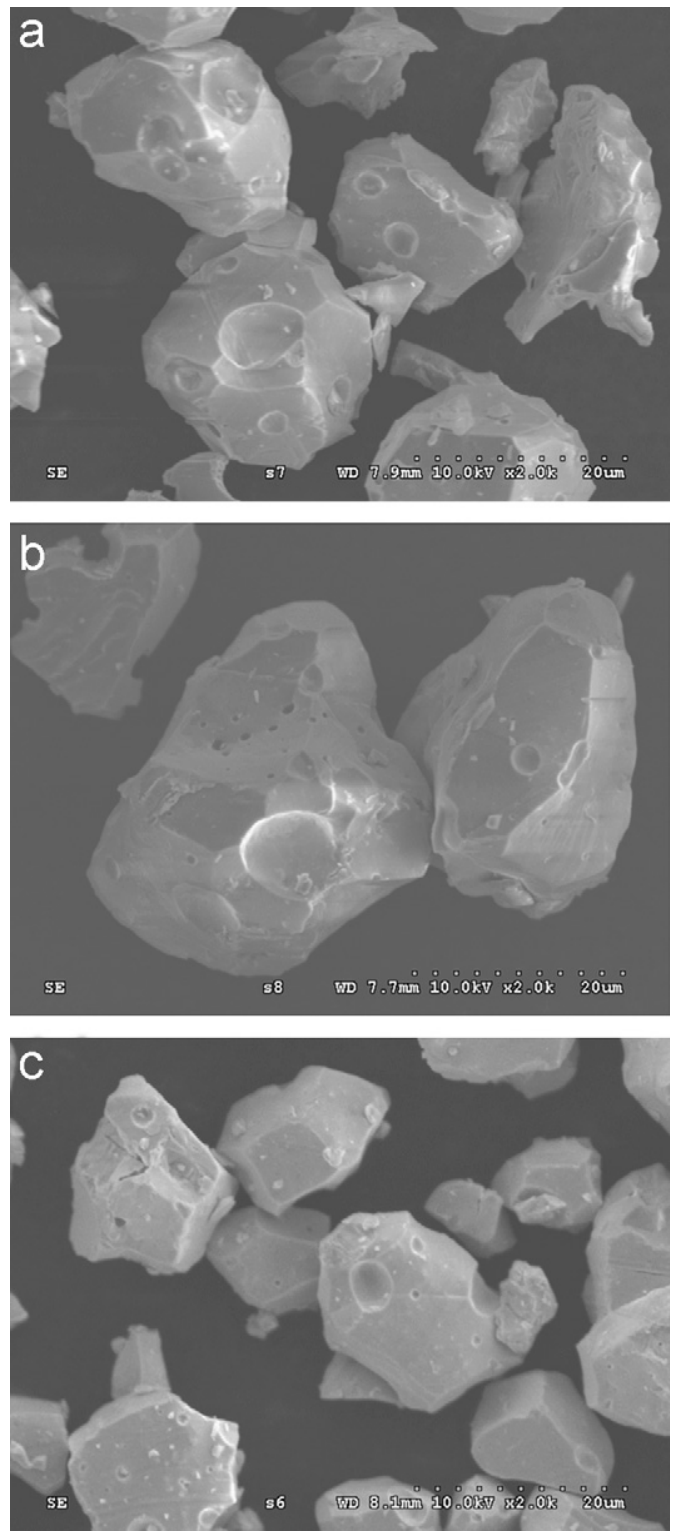

Fig. 2. Morphologies of $\mathrm{Ag}_{3} \mathrm{VO}_{4}$ prepared (a) in the presence of excess silver, (b) in a stoichiometric ratio, and (c) in the presence of excess vanadium.

conditions. The photocatalytic process was the predominant process for the degradation of ARB under all the experimental conditions. Furthermore, ARB had almost same adsorption (about 5\%) on the three samples, indicating that difference of photodegradation of ARB was not due to the adsorption of dyes on the surface of photocatalysts. The photocatalytic activity greatly depended on the morphology and structure of $\mathrm{Ag}_{3} \mathrm{VO}_{4}$. Generally, the rate of the photocatalytic reaction is proportional to $\left(I_{\alpha} \phi\right)^{n}$ ( $n=1$ for low light intensity and $n=\frac{1}{2}$ for high light intensity), where $I_{\alpha}$ is the photo numbers absorbed by photocatalyst per second and $\phi$ is the efficiency of the band gap transition [28]. The enhancement of the photoreactivity with excess silver and vanadium can be partly explained in terms of an increase in $I_{\alpha} \phi$ resulting

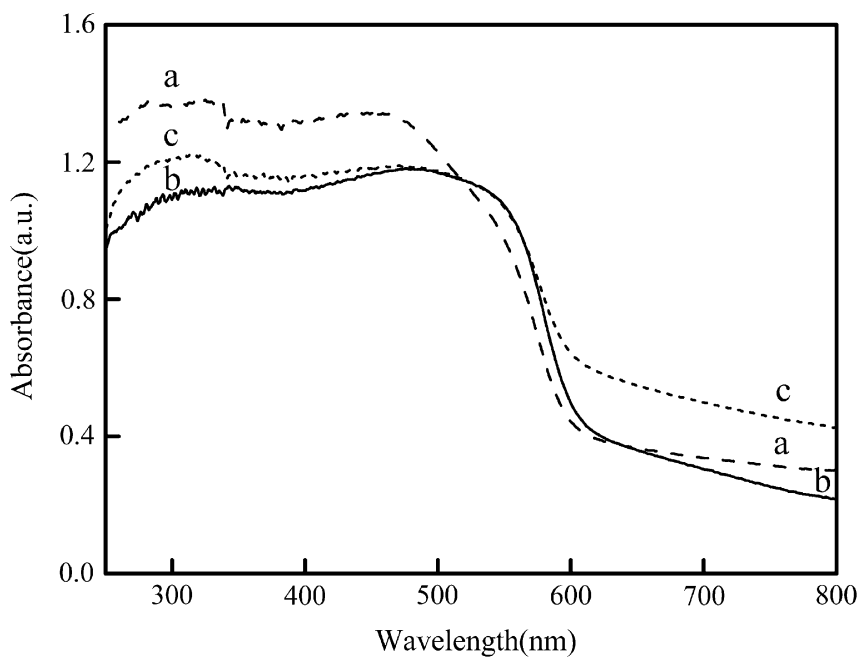

Fig. 3. UV-vis diffuse reflectance spectra of samples (a) in the presence of excess silver, (b) in a stoichiometric ratio, and (c) in the presence of excess vanadium.

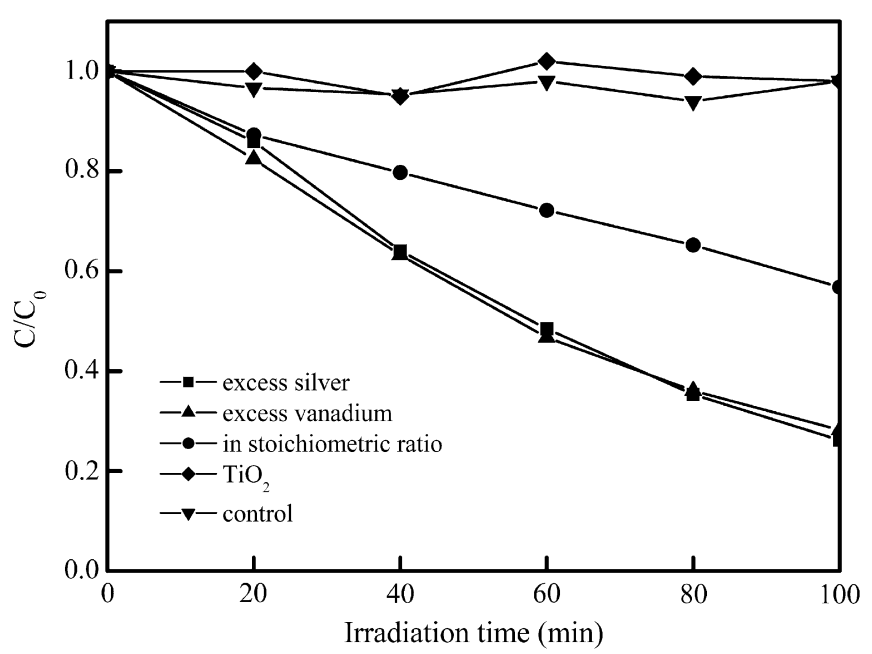

Fig. 4. Temporal course of the photodegradation of ARB in aqueous dispersions containing $0.1 \mathrm{~g}$ of catalysts under visible light irradiation.

from intensity absorbance in the visible region of $420-580 \mathrm{~nm}$, which could increase the number of photogenerated electrons and holes to participate in the photocatalytic reaction. Moreover, the well-crystallinity of $\mathrm{Ag}_{3} \mathrm{VO}_{4}$ prepared in the excess silver or vanadium favored the separation of electron-hole pair. In addition, $\mathrm{Ag}_{2} \mathrm{O}$ on the surface of the catalyst mainly act as electron traps, enhancing the electron-hole separation, leading the higher photocatalytic activity. Therefore, the sample prepared in the excess silver showed higher activity. As for the sample in stoichiometric ratio, due to the bigger particles size and lower crystallinity, the recombination of the photogenerated electron and hole was still predominant, resulting in the lower photocatalytic activity.

The stability of a photocatalyst is important to its application. Therefore, after the aqueous suspension of S3 


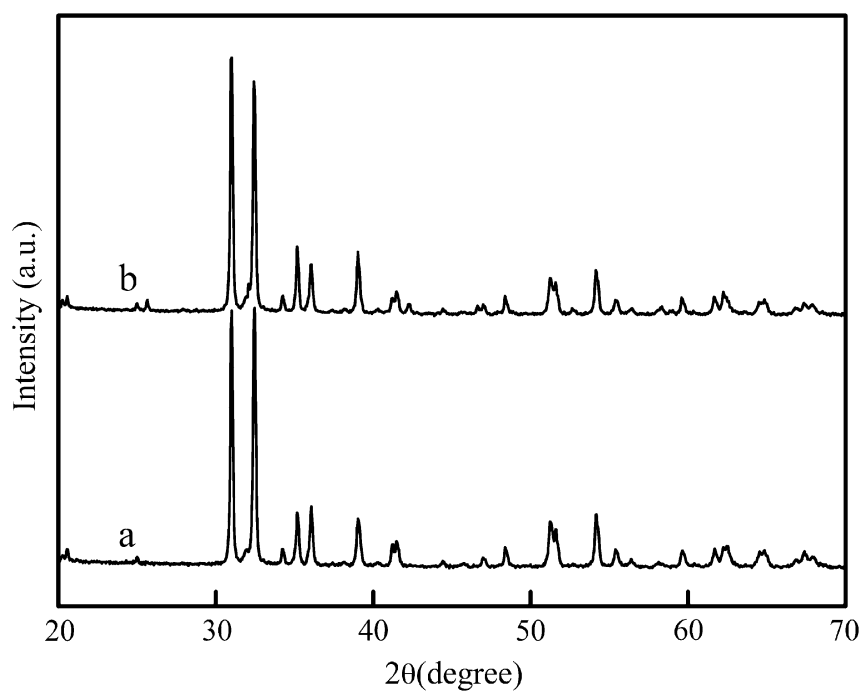

Fig. 5. XRD patterns of $\mathrm{Ag}_{3} \mathrm{VO}_{4}$ in excess vanadium (a) fresh and (b) after UV and visible irradiation.

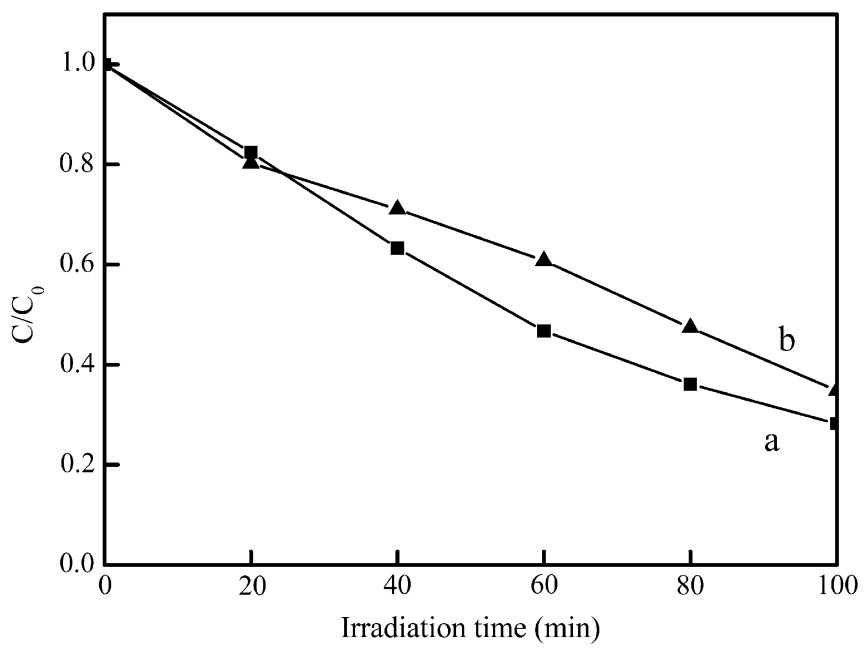

Fig. 6. The degradation of ARB under visible light with different catalysts: (a) fresh $\mathrm{Ag}_{3} \mathrm{VO}_{4}$ and (b) $\mathrm{Ag}_{3} \mathrm{VO}_{4}$ after UV and visible light irradiation.

was irradiated by UV and visible light, the dried $\mathrm{Ag}_{3} \mathrm{VO}_{4}$ sample was characterized by XRD (Fig. 5). The crystal structure of the $\mathrm{Ag}_{3} \mathrm{VO}_{4}$ photocatalyst was not changed before and after irradiation. The catalyst's activity was maintained effectively after irradiated by UV and visible light irradiation (Fig. 6). This result implies that $\mathrm{Ag}_{3} \mathrm{VO}_{4}$ is stable in aqueous solution and under irradiation.

\subsection{Effects of cocatalysts on the photocatalytic activity}

In order to enhance the photocatalytic activities, the $\mathrm{Ag}_{3} \mathrm{VO}_{4}$ prepared in excess vanadium was chosen to load a $\mathrm{NiO}$ cocatalyst by impregnation method. In $\mathrm{Ag}_{3} \mathrm{VO}_{4}$ or $\mathrm{NiO} / \mathrm{Ag}_{3} \mathrm{VO}_{4}$ system, the plot of $\ln \left(C_{0} / C\right)$ vs. time results in

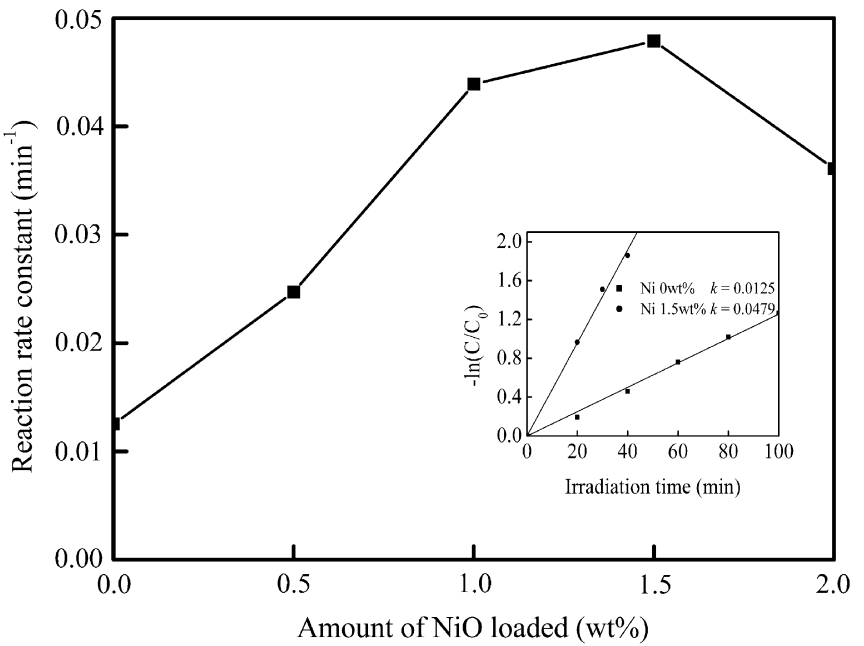

Fig. 7. The reaction constant $k$ as a function of $\mathrm{Ni}$ content in $\mathrm{NiO} /$ $\mathrm{Ag}_{3} \mathrm{VO}_{4}$ prepared in the presence of excess vanadium. The inset shows first-order plots for the photocatalytic degradation of ARB using $\mathrm{Ag}_{3} \mathrm{VO}_{4}$ and $\mathrm{Ni} 1.5 \mathrm{wt} \% / \mathrm{Ag}_{3} \mathrm{VO}_{4}$.

a straight line (inset of Fig. 7), which indicated that the decolorization of $\mathrm{ARB}$ in the $\mathrm{Ag}_{3} \mathrm{VO}_{4}$ or $\mathrm{NiO} / \mathrm{Ag}_{3} \mathrm{VO}_{4}$ system followed the pseudo-first-order kinetics. Fig. 7 shows the reaction constant $k$ as a function of $\mathrm{Ni}$ content in $\mathrm{NiO} / \mathrm{Ag}_{3} \mathrm{VO}_{4}$ for the degradation of $\mathrm{ARB}$ under visible light irradiation. With the loading amount of $\mathrm{NiO}$ increasing, the reaction constant of ARB increased and reached a certain value at $\mathrm{Ni} 1.5 \mathrm{wt} \%$, in which the reaction constant was increased by 3.8 times. And then the degradation rate decreased when the amount of $\mathrm{NiO}$ was further increased. The results indicated that the loading amount of $\mathrm{NiO}$ existed optimum value. The appropriate $\mathrm{NiO}$ loading amount trapped the larger number of photoexcited electrons, resulting in the increase in the photocatalytic activity. The excess $\mathrm{NiO}$ would be recombination center decreasing the photocatalytic activity. On the other hand, in this experiment, it was found that $\mathrm{NiO}$ did not show any activity for the ARB degradation under visible light irradiation. So, the excess $\mathrm{NiO}$ particles might cause the decrease in the light absorption capability of the catalyst and accordingly lower the photoexcitation to generate the active electrons [29]. Fig. 8 shows the durability of the optimum catalyst $\mathrm{Ni} 1.5 \mathrm{wt} \% / \mathrm{Ag}_{3} \mathrm{VO}_{4}$ $\left(\mathrm{NiO} / \mathrm{Ag}_{3} \mathrm{VO}_{4}\right)$ for the degradation of $\mathrm{ARB}$ under visible light. Catalyst was easily recycled by simple filtration without any treatment in these experiments. The photocatalytic activity did not decrease significantly in the degraded ARB after five successive cycles under visible irradiation. The results demonstrated that $\mathrm{NiO} / \mathrm{Ag}_{3} \mathrm{VO}_{4}$ is an effective and stable catalyst.

Fig. 9 shows the UV/vis spectral changes of ARB solution recorded for $\mathrm{NiO} / \mathrm{Ag}_{3} \mathrm{VO}_{4}$ as a function of irradiation time. The ARB characteristic band centered at $514 \mathrm{~nm}$ was decreased promptly upon light irradiation, and decolorized completely after $100 \mathrm{~min}$ of irradiation, indicating that at least the chromophoric structure of the dye 


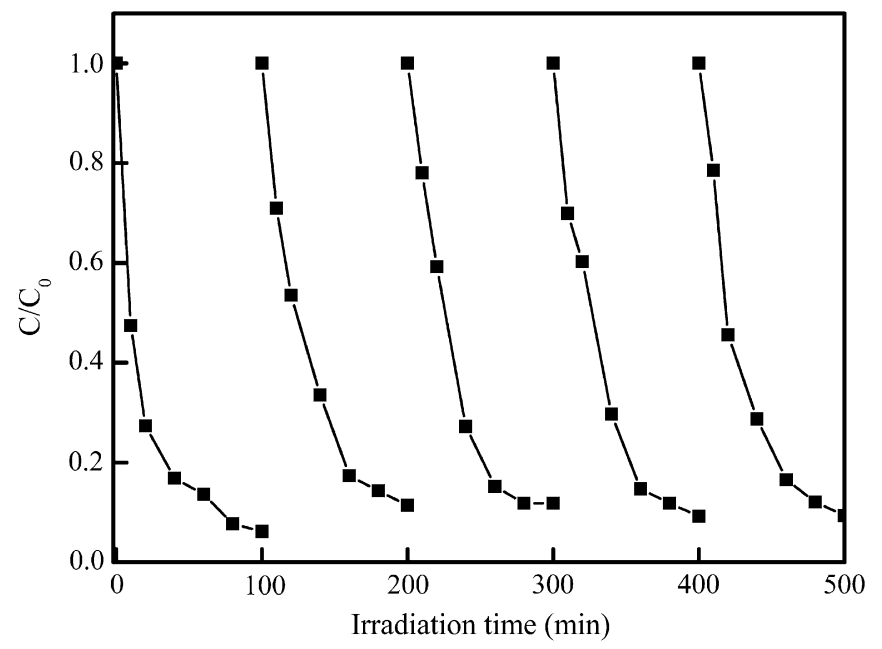

Fig. 8. Cycling runs in the photodegradation of ARB in the presence of $\mathrm{NiO} / \mathrm{Ag}_{3} \mathrm{VO}_{4}$ under visible light irradiation.

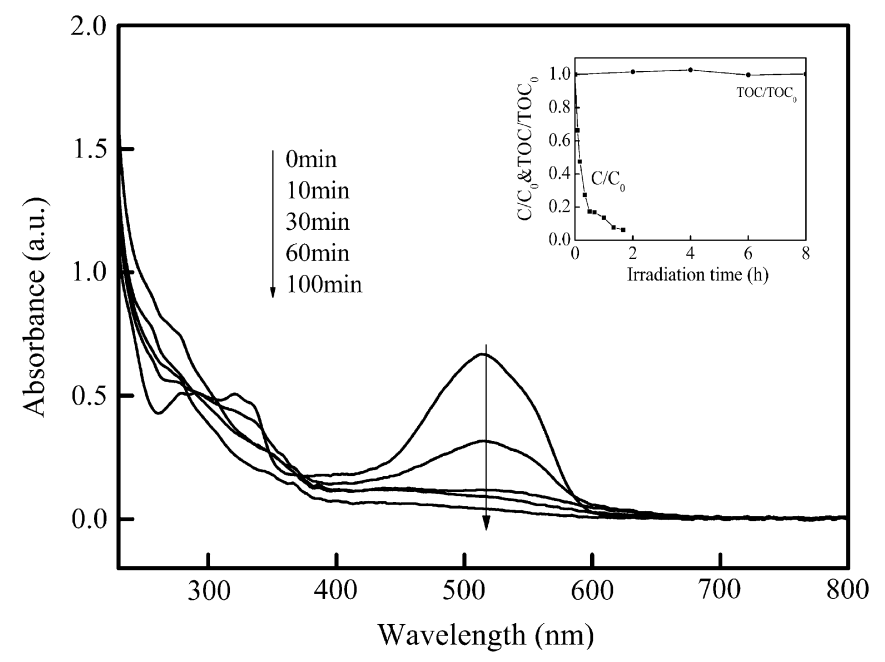

Fig. 9. The UV/vis spectral changes of ARB solution recorded for $\mathrm{NiO} /$ $\mathrm{Ag}_{3} \mathrm{VO}_{4}$ as a function of irradiation time. The inset shows the changes of concentration of $\mathrm{ARB}$ and the removal of TOC in the system of $\mathrm{NiO} /$ $\mathrm{Ag}_{3} \mathrm{VO}_{4}$.

was destroyed, and other intermediates were formed. However, TOC measurements showed almost no change in the total organic content before and after photooxidation (inset plot in Fig. 9), indicating that the process is a selective oxidation rather than a mineralization. The oxidation products of $\mathrm{ARB}$ in the photocatalytic reaction were identified by GC-MS. The identified products included phthalic acid, acetic acid. The highly selective photooxidation of the catalyst for different dyes would be shown in another paper.

\subsection{The role mechanism of cocatalysts}

To illustrate the role mechanism of $\mathrm{NiO}$ in enhancing the activity of $\mathrm{Ag}_{3} \mathrm{VO}_{4}$, the optimum catalyst $\mathrm{NiO} / \mathrm{Ag}_{3} \mathrm{VO}_{4}$ was characterized by XRD, SEM, XPS and ESR. The addition of $\mathrm{NiO}$ had no influence on the crystal structure of

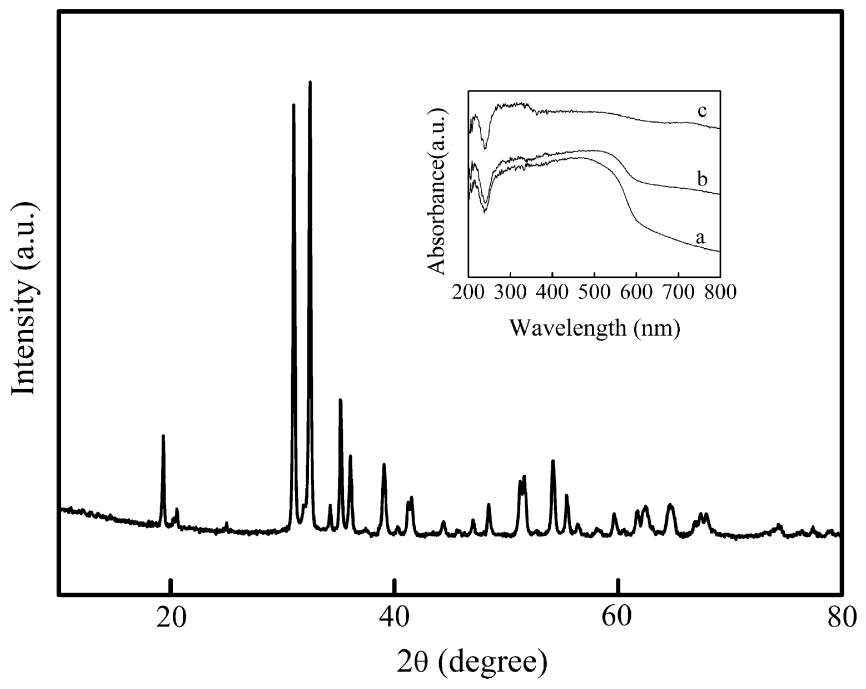

Fig. 10. XRD spectra of $\mathrm{NiO} / \mathrm{Ag}_{3} \mathrm{VO}_{4}$ photocatalyst. The inset shows UV-vis diffuse reflectance spectra of the samples: (a) $\mathrm{Ag}_{3} \mathrm{VO}_{4}$, (b) $\mathrm{NiO} /$ $\mathrm{Ag}_{3} \mathrm{VO}_{4}$, and (c) $\mathrm{NiO}$.

$\mathrm{Ag}_{3} \mathrm{VO}_{4}$ (Fig. 10). No XRD diffraction peaks of oxide nickel species were observed at $\mathrm{NiO} / \mathrm{Ag}_{3} \mathrm{VO}_{4}$ samples. This was presumably due to the combination of its low content, small particle size and high dispersion on the surface of the $\mathrm{Ag}_{3} \mathrm{VO}_{4}$ particle. Determination of the oxidation state of nickel was carried out by measuring $\mathrm{Ni} 2 p_{3 / 2}$ binding energy (BE) with XPS. The BE 854.0 was assigned to $\mathrm{NiO}$. The inset of Fig. 10 shows the UV-vis absorbance spectra of the samples. With the loading of $\mathrm{NiO}$, the $\mathrm{NiO} / \mathrm{Ag}_{3} \mathrm{VO}_{4}$ displayed the same absorption edge as $\mathrm{Ag}_{3} \mathrm{VO}_{4}$. However, $\mathrm{NiO} / \mathrm{Ag}_{3} \mathrm{VO}_{4}$ specimens exhibited a greater light absorption throughout the visible wavelengths due to the grayed color of the catalyst. Fig. 11a shows the SEM images of the $\mathrm{NiO} / \mathrm{Ag}_{3} \mathrm{VO}_{4}$. NiO particles were uniformly distributed on the surface of $\mathrm{Ag}_{3} \mathrm{VO}_{4}$. The composition of this catalyst was analyzed with energy-dispersive X-ray (EDX) as shown in Fig. 11b. Ag, V, O, and Ni lines were observed. The concentration of $\mathrm{Ni}$ was about $4.01 \mathrm{wt} \%$, which was more than the dosages of $1.5 \mathrm{wt} \%$. The result demonstrated that most $\mathrm{NiO}$ was localized on the surface of the $\mathrm{Ag}_{3} \mathrm{VO}_{4}$. The atomic ratio of $\mathrm{Ag} / \mathrm{V}$ in the structure of the sample was $37.19: 12.35$, which is close to the ideal value of $3: 1$ and agrees with the result of XRD. The results confirmed that only $\mathrm{NiO}$ and $\mathrm{Ag}_{3} \mathrm{VO}_{4}$ are present, without formation of a mixed oxide system. ESR studies were also performed (Fig. 12). The six characteristic peaks of the DMPO-O ${ }_{2}^{-}$ adducts were observed only in $\mathrm{NiO} / \mathrm{Ag}_{3} \mathrm{VO}_{4}$ methanol dispersion under visible light irradiation (curve a). No such signals were detected in the dark (curve c) and visible-lightirradiated $\mathrm{Ag}_{3} \mathrm{VO}_{4}$ system (curve b) under otherwise identical conditions. No $\mathrm{O}_{2}^{-} \bullet$ was formed in the visiblelight-illuminated $\mathrm{Ag}_{3} \mathrm{VO}_{4}$ methanol suspension, indicating that the recombination rate of the photogenerated electron-hole pairs from the $\mathrm{Ag}_{3} \mathrm{VO}_{4}$ excited by visible light was higher than that one of their separation. The evidence that $\mathrm{O}_{2}^{-} \bullet$ radicals are produced on the surface of visible 

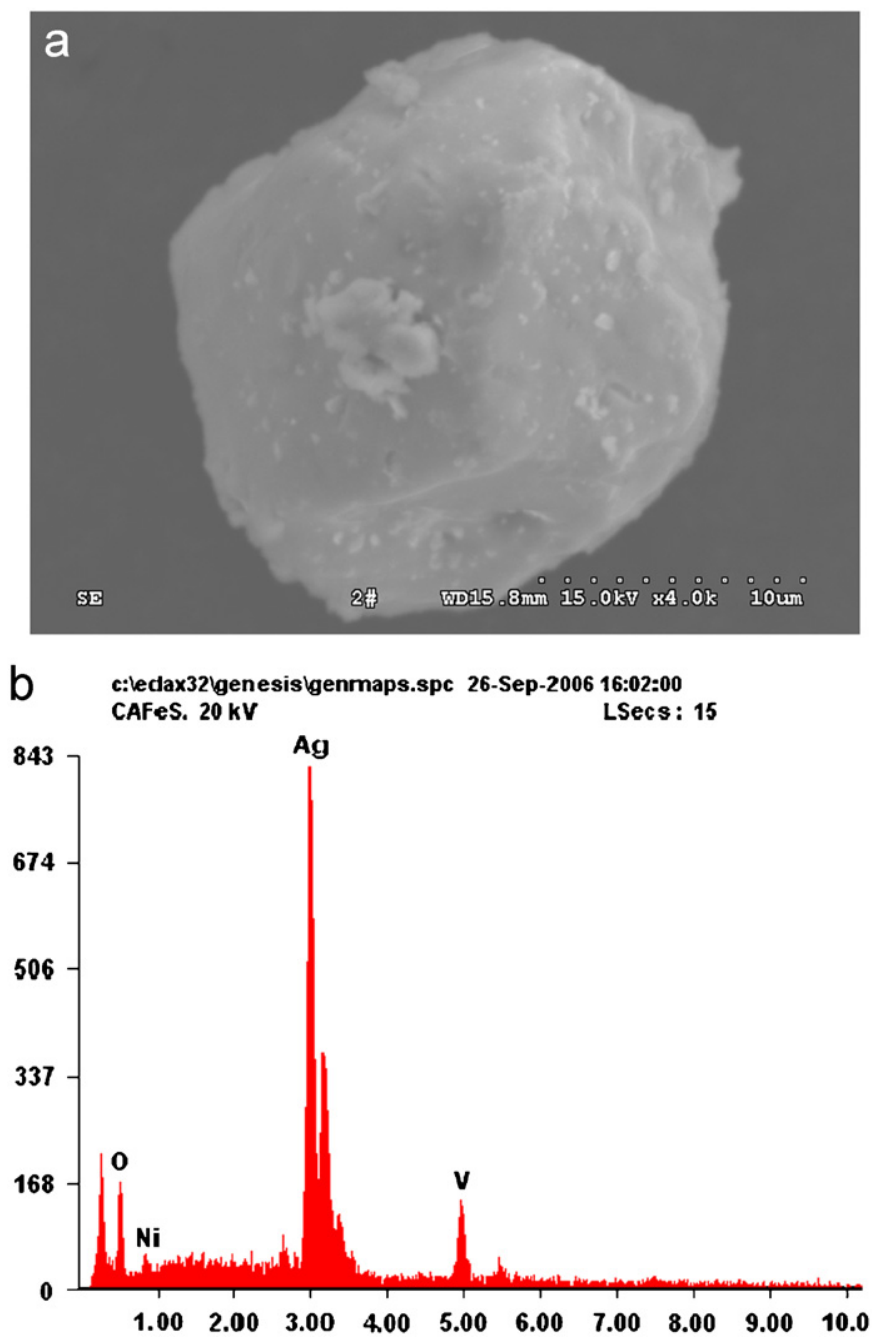

Fig. 11. (a) SEM image and (b) EDX analysis of $\mathrm{NiO} / \mathrm{Ag}_{3} \mathrm{VO}_{4}$ photocatalyst.

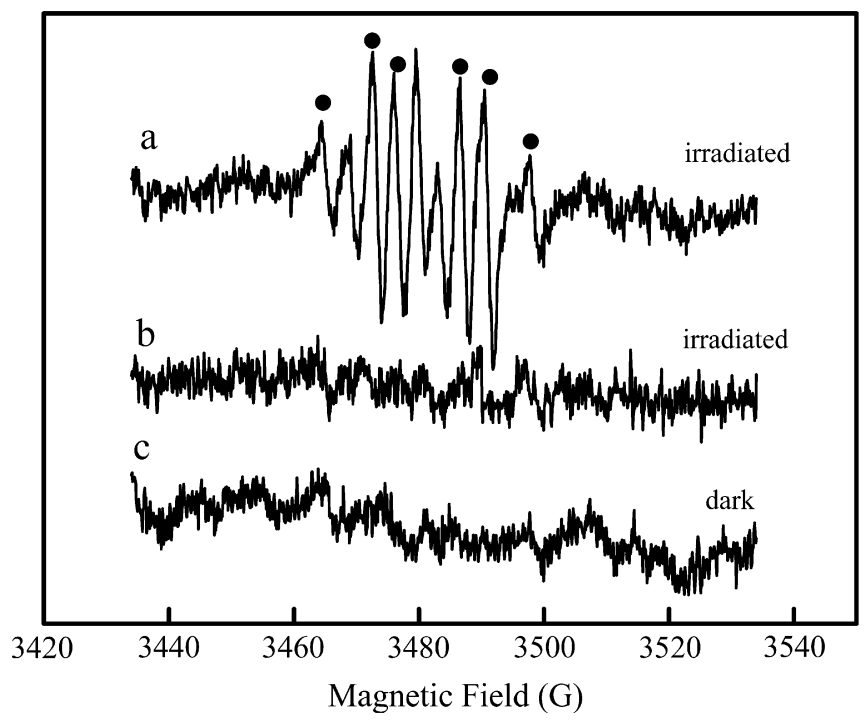

Fig. 12. DMPO spin-trapping ESR spectra recorded at ambient temperature in methanol dispersion under visible light irradiation (532 nm): (a) $\mathrm{NiO} / \mathrm{Ag}_{3} \mathrm{VO}_{4}$ and (b) $\mathrm{Ag}_{3} \mathrm{VO}_{4}$ under visible light irradiation and (c) $\mathrm{NiO} / \mathrm{Ag}_{3} \mathrm{VO}_{4}$ in dark. illuminated $\mathrm{NiO} / \mathrm{Ag}_{3} \mathrm{VO}_{4}$ provides a solid indication that the catalyst can be efficiently excited by visible light to create electron-hole pairs and that the charge separation is maintained long enough to react with adsorbed oxygen/ $\mathrm{H}_{2} \mathrm{O}$ and to produce active oxygen radicals which finally induce the decomposition of pollutants [30,31]. All the above results confirmed that the $\mathrm{NiO} / \mathrm{Ag}_{3} \mathrm{VO}_{4}$ system behaves as a short-circuited microphotoelectrochemical cell. In the system of $\mathrm{NiO} / \mathrm{Ag}_{3} \mathrm{VO}_{4}$, the surface of $\mathrm{NiO}$ is the cathode, and the surface of $\mathrm{Ag}_{3} \mathrm{VO}_{4}$ is the anode. The $\mathrm{NiO}$ on the external surface of $\mathrm{Ag}_{3} \mathrm{VO}_{4}$ trapped photogenerated electrons, facilitating the electron-hole separation leading to more active species formation, resulting in the enhancement of photocatalytic activity of $\mathrm{Ag}_{3} \mathrm{VO}_{4}$.

\section{Conclusions}

$\mathrm{Ag}_{3} \mathrm{VO}_{4}$ prepared by precipitation method in the excess silver or vanadium exhibited high visible-light-driven activity. The excess vanadium or silver in the preparation increased the crystallinity and absorbance in visible light region to produce more electron-hole pairs, resulting in an increase in the photocatalytic activity. Furthermore, the activity of the $\mathrm{Ag}_{3} \mathrm{VO}_{4}$ was increased by 3.8 times when a $\mathrm{NiO}$ catalyst was loaded on its surface. It is contributed to $\mathrm{NiO}$ facilitating the excited electron transfer and hence suppressing efficiently the recombination of photogenerated electron-hole.

\section{Acknowledgments}

This work was supported by the National Science Foundation of China (20537020, 20377050, 20577062, 50538090).

\section{References}

[1] M.R. Hoffman, S.T. Martin, W. Choi, D.W. Bahnemann, Chem. Rev. 95 (1995) 69-96.

[2] A.B. Prevot, C. Baiocchi, M.C. Brussino, E. Pramauro, P. Savarino, V. ugugliaro, G. Marci, L. Palmisano, Environ. Sci. Technol. 35 (2001) 971-976.

[3] D.S. Muggli, L. Ding, M.J. Odland, Catal. Lett. 78 (2002) 23-31.

[4] A.A. Belhekar, S.V. Awate, R. Anand, Catal. Commun. 3 (2002) 453-458.

[5] A. Linsebigler, G. Lu, J. Yates, Chem. Rev. 95 (1995) 735-758.

[6] C. Wang, J. Zhao, X. Wang, B. Mai, G. Sheng, P. Peng, J. Fu, Appl. Catal. B: Environ. 39 (2002) 269-279.

[7] W. Zhao, C. Chen, X. Li, J. Zhao, H. Hidaka, N. Serpone, J. Phys. Chem. B 106 (2002) 5022-5028.

[8] D. Li, H. Haneda, J. Photochem. Photobiol. A: Chem. 155 (2003) 171-178.

[9] J. Wang, S. Uma, K. Klabunde, Appl. Catal. B: Environ. 48 (2004) $151-154$.

[10] I. Martyanov, S. Uma, D. Rodrigues, K. Klabunde, Chem. Commun. 21 (2004) 2476-2477.

[11] H. Irie, Y. Watanabe, K. Hashimoto, Chem. Lett. 32 (2003) 772-773.

[12] M. Anpo, M. Takeuchi, J. Catal. 216 (2003) 505-516.

[13] J.W. Tang, Z.G. Zou, J.H. Ye, Angew. Chem. 116 (2004) 4563-4566.

[14] Z.G. Zou, J.H. Ye, K. Sayama, H. Arakawa, Nature 424 (2001) 625-627. 
[15] A. Ishikawa, T. Takata, T. Matsumura, J.N. Kondo, M. Hara, H. Kobayashi, K. Domen, J. Phys. Chem. B. 108 (2004) 2637-2642.

[16] D. Wang, J.W. Tang, Z.G. Zou, J.H. Ye, Chem. Mater. 17 (2005) 5177-5182.

[17] J.H. Ye, Z.G. Zou, M. Oshikiri, A. Matsushita, M. Shimoda, M. Imai, T. Shishido, Chem. Phys. Lett. 356 (2002) 221-226.

[18] J.W. Tang, Z.G. Zou, J.H. Ye, J. Phys. Chem. B 107 (2003) $14265-14269$

[19] J.H. Ye, Z.G. Zou, A. Matsushita, Int. J. Hydrogen Energy 28 (2003) 651-655.

[20] J. Yu, J. Xiong, B. Cheng, Y. Yu, J. Wang, J. Solid State Chem. 178 (2005) 1976-1980.

[21] J.W. Tang, Z.G. Zou, J. Yin, J.H. Ye, Chem. Phys. Lett. 382 (2003) $175-179$.

[22] L. Zhang, D. Chen, X. Jiao, J. Phys. Chem. B 110 (2006) 2668-2673.
[23] R. Konta, H. Kato, H. Kobayoshi, A. Kudo, Phys. Chem. Chem. Phys. 5 (2003) 3061-3065.

[24] J.W. Tang, Z.G. Zou, J.H. Ye, Catal. Lett. 92 (2004) 53-56.

[25] H.M. Martin, Photodegradation of Water Pollutant, CRC Press, Boca Raton, FL, 1996.

[26] H. Kato, H. Kobayashi, A. Kudo, J. Phys. Chem. B 106 (2002) 12441-12447.

[27] C. Kormann, D.W. Bahnemann, M.R. Hoffmann, J. Phys. Chem. 92 (1988) 5196-5201.

[28] J.C. Yu, J.G. Yu, W. Ho, Z.T. Jiang, L.Z. Zhang, Chem. Mater. 14 (2002) 3808-3816.

[29] T. Sreethawong, Y. Suzuki, S. Yoshikawa, Int. J. Hydrogen Energy 30 (2005) 1053-1062.

[30] Z.G. Zou, J.H. Ye, H. Arakawa, J. Phys. Chem. B 106 (2002) 13098-13101.

[31] J. Zou, C. Liu, Y. Zhang, Langmuir 22 (2006) 2334-2339. 